\title{
Steroid hormone (20-hydroxyecdysone) modulates the acquisition of aversive olfactory memories in pollen forager honeybees
}

\author{
Lisa H. Geddes, H. James McQuillan, Alastair Aiken, Vanina Vergoz, and Alison R. Mercer ${ }^{1}$ \\ Department of Zoology, University of Otago, Dunedin, New Zealand 9054
}

\begin{abstract}
Here, we examine effects of the steroid hormone, 20-hydroxyecdysone (20-E), on associative olfactory learning in the honeybee, Apis mellifera. 20-E impaired the bees' ability to associate odors with punishment during aversive conditioning, but did not interfere with their ability to associate odors with a food reward (appetitive learning). The steroid had a significant impact also on the expression of amine-receptor genes in centers of the brain involved in the formation and recall of associative olfactory memories (mushroom bodies). 20-E increased expression of the dopamine receptor gene, Amdop2, and reduced the expression of the putative dopamine/ecdysone receptor gene, Amgpcr19. Interestingly, Amgpcr19 tended to be highly expressed in the brains of foragers that exhibited strong aversive learning, but expressed at lower levels in bees that performed well in appetitive learning assays. In 2-d-old bees, transcript levels of the same gene could be reduced by queen mandibular pheromone, a pheromone that blocks aversive learning in young worker bees. As ecdysteroid levels rise to a peak $\sim 2 \mathrm{~d}$ after adult emergence and then fall to low levels in foragers, we examined aversive learning also in young worker bees. Aversive learning performance in 2-d-old bees was consistently poor. The results of this study indicate that learning in honeybees can be modulated by ecdysteroids. They highlight, in addition, a potential involvement of the putative dopamine/ecdysone receptor, AmGPCR19, in hormonal regulation of associative olfactory learning in the honeybee.
\end{abstract}

Ecdysteroids have long been known to play a critical role in insect development and reproduction (for reviews, see Riddiford et al. 2000; Truman and Riddiford 2002; Raikhel et al. 2004; Gruntenko and Rauschenbach 2008). However, steroid hormone signaling has recently been implicated also in memory formation in insects (Ishimoto et al. 2009). Drosophila mutants with disrupted ecdysone signaling exhibit long-term memory (LTM) impairments, and administration of 20-hydroxyecdysone (20-E), an active metabolite of ecdysone, has been found to alter long-term courtship memory in the fly (Ishimoto et al. 2009). There is evidence that ecdysteroids also regulate the behavior of adult worker honeybees. Genes involved in ecdysteroid signaling are preferentially expressed in the mushroom bodies of the bee brain (e.g., Paul et al. 2005, 2006; Velarde et al. 2006, 2009; Yamazaki et al. 2006, 2011; Takeuchi et al. 2007), and intrinsic mushroom body neurons (Kenyon cells) of adult worker bees have been shown to respond to ecdysteroids with a predictable cascade of gene expression (Velarde et al. 2009). Interestingly, a recent report shows that ecdysone is converted into 20-E not only in fat bodies, but also in the brain of the honeybee, suggesting that ecdysteroids may function as neurohormones in this insect (Yamazaki et al. 2011).

As ecdysteroid signaling has been identified in the mushroom bodies of honeybees, brain centers known to play a critical role in the formation and recall of associative olfactory memories (Menzel and Müller 1996, 2001; Müller 2006; Giurfa 2007; Giurfa and Sandoz 2012), we were interested in determining whether ecdysteroids influence memory formation in adult worker bees. Here, we examine the effects of exogenously applied 20-E on associative olfactory learning in forager bees trained to associate an odor with either a food reward (appetitive learning) or with pun-

'Corresponding author

E-mail alison.mercer@otago.ac.nz

Article is online at http://www.learnmem.org/cgi/doi/10.1101/lm.030825.113. ishment (aversive learning), and we compare aversive learning performance in foragers with learning in bees 2-4 d after adult emergence, when endogenous ecdysteroid levels have been found to be naturally high (Hartfelder et al. 2002; Amdam et al. 2010). We investigate, in addition, the effects of 20-E on the expression of amine-receptor genes that are strong candidates to play a role in associative olfactory learning in the honeybee, and compare levels of expression of these genes in the brains of good and poor learners. In addition to the honeybee dopamine receptor genes, Amdop1, Amdop2, and Amdop3, and the octopamine receptor gene, Amoa1, we include in our analysis the putative dopamine/ecdysone receptor gene, Amgpcr19 (Apis mellifera GProtein-Coupled Receptor, \#19), which is the honeybee ortholog of the dopamine/ecdysone receptor gene (DmDopEcR) identified in Drosophila (Srivastava et al. 2005). As well as showing that 20-E modulates olfactory learning in the honeybee, our study identifies AmGPCR19 as a candidate for involvement in ecdysteroid modulation of associative olfactory learning behavior in the honeybee.

\section{Results}

Appetitive learning in foragers is not affected significantly by $20-\mathrm{E}$

Control (untreated) bees, bees injected with vehicle (Ringer containing 3.2\% ethanol), and 20-E-treated bees all showed robust appetitive learning (Fig. 1A-D). In all three groups, the percentage of bees displaying a proboscis extension response (PER) to CS + increased significantly over the six conditioning trials (control, $Q=$ 78.065, $\mathrm{DF}=5, P<0.001$; vehicle, $Q=66.238, \mathrm{DF}=5, P<0.001$; 20-E, $Q=54.942, \mathrm{DF}=5, P<0.001$ ) (Fig. $1 \mathrm{Ai}-\mathrm{Ci}$ ), and in all three groups responses to $\mathrm{CS}+$ in the retention test were significantly higher than responses to unconditioned stimulus (US) (control 

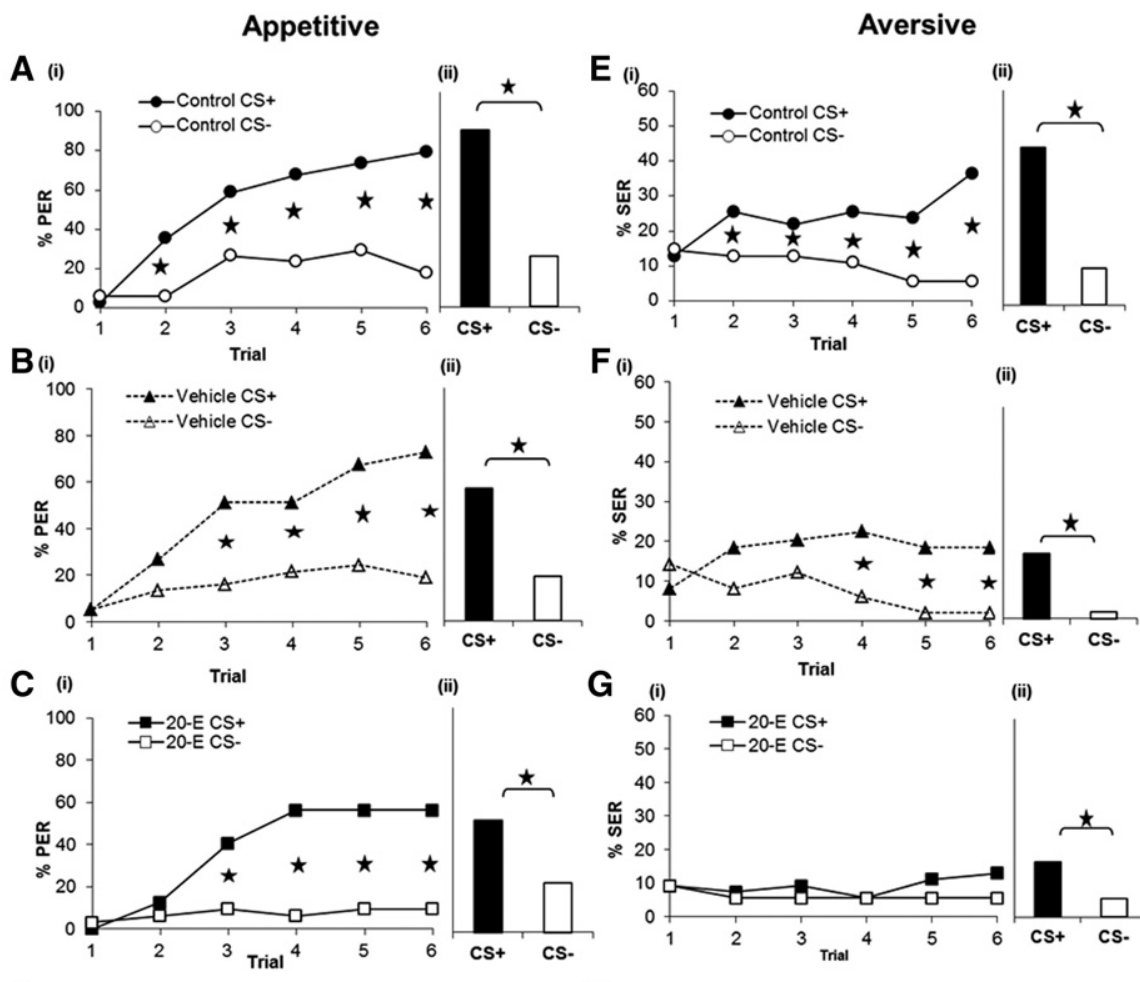

$\mathbf{F}_{(i)}$

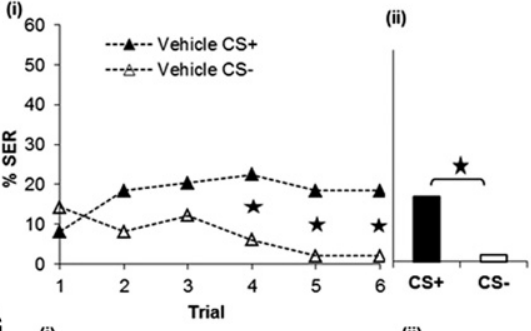

G
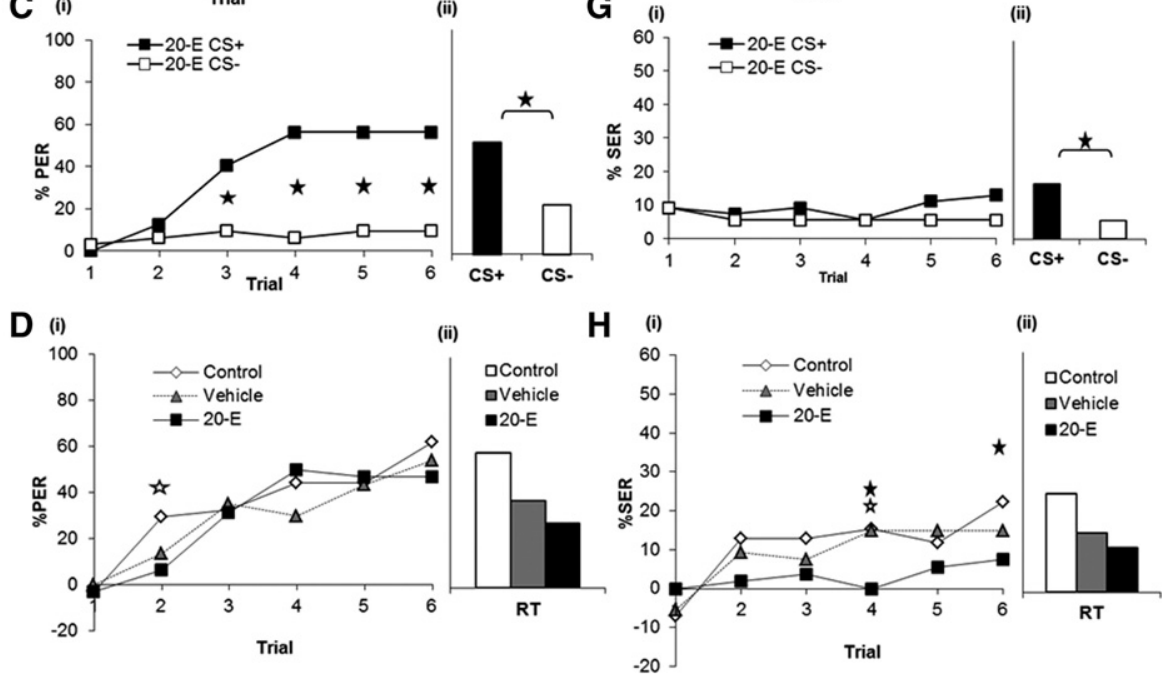

Figure 1. Associative olfactory learning in control (untreated) forager bees $(A, E)$ and in bees treated with vehicle alone (Bee Ringer containing 3.2\% ethanol $[B, F])$, or with vehicle plus 20-E (C, G). (Ai-Hi) Acquisition curves show the percentage of bees displaying a conditioned response (percentage proboscis extension response [PER] $[A-D]$ or percentage sting extension response [SER] $[E-H])$ in response to an odor $(C S+)$ paired with food reward $(A-D$, black symbols) or with electric shock $(E-H$, black symbols), and to a second odor (CS - ) that was not reinforced ( $A-H$, nonfilled symbols). (Aii-Hii) Percentage of bees responding to the reinforced odor ( $C S+$, black bars) and the nonreinforced odor (CS -, white bars) $1 \mathrm{~h}$ after the last conditioning trial (retention test [RT]). ( $\left.{ }^{*}\right)$ Significant differences between the level of responses to $\mathrm{CS}+$ and $\mathrm{CS}-$. Difference scores (percentage responding to CS+ minus percentage responding to $\mathrm{CS}-$ ) during acquisition $(\mathrm{Di}, \mathrm{Hi})$, and in the retention tests (RT) (Dii,Hii), for appetitive learning and aversive learning, respectively. $(H)\left(^{*}\right)$ Significant difference between the difference scores obtained for controls and 20 -E-treated bees. $(D, H)$ (Nonfilled asterisks) Significant difference between the difference scores obtained for vehicle- and 20-E-treated bees.

and vehicle, $P<0.001 ; 20$-E, $P=0.022$ ) (Fig. 1Aii-Cii). From the second trial onward in the control group, and from the third trial onward in vehicle- and 20-E-treated bees, the percentage of bees responding to CS + was significantly greater than the percentage responding to CS - (Fig. 1Ai-Ci). Difference scores (percentage of bees responding to $\mathrm{CS}+$ minus percentage of bees responding to $\mathrm{CS}-$ ) were also similar across the three groups (Fig. 1Di,ii), with the exception of the second conditioning trial in which the difference score recorded in the controls was higher than that for bees treated with steroid $(P=0.0160)$ (Fig. 1Di). The percentage of bees that never displayed a conditioned response was also similar in controls, vehicle-treated bees, and bees treated with 20-E (Fig. 2Ai). However, there was evidence of effects of vehicle and 20-E on appetitive learning. Responses to $\mathrm{CS}+$, for example, were generally lower in these groups (Fig. 1B,C). In addition, a significant difference was identified across the three treatment groups in the proportion of bees excluded from appetitive conditioning based on their failure to display proboscis extension in response to stimulation of the antennae with sucrose (linear regression [lreg], main effect, $P<0.001$ ) (Fig. 2Bi). Although the differences between individual treatment groups were not statistically significant, there were strong trends suggesting that a higher proportion of 20-E-treated bees were excluded than controls $(P=0.056)$ or vehicle-treated bees $(P=0.074)$.

\section{0-E modulates aversive learning behavior in forager bees}

During aversive conditioning, the percentage of control bees displaying a sting extension response (SER) to CS+ increased significantly over the six aversive conditioning trials $(Q=16.835, \mathrm{DF}=5$, $P=0.005$ ) (Fig. 1Ei). Responses to CS+ increased during conditioning in vehicle-treated bees also, but changes in responsiveness to $\mathrm{CS}+$ during the acquisition phase were not statistically significant for this group $(P=0.279)$ (Fig. 1Fi). However, there was a significant decline in responses to $\mathrm{CS}$ - in vehicle-treated bees $(Q=13.056, \quad D F=5, \quad P=0.023)$ (Fig. 1Fi) and vehicle-treated bees, like controls, showed clear differentiation of CS + and CS - . The level of responses to CS+ was significantly higher than the level of responses to the unreinforced odor (CS-) from the second conditioning trial onward in the case of control bees (Fig. 1Ei), and from the fourth trial onward in the vehicle-only group (Fig. 1Fi). The level of responses to CS+ was also significantly higher than that to $\mathrm{CS}$ - in the retention test, both in controls and in vehicle-treated bees (control, $P<0.001$; vehicle, $P=0.021$ ) (Fig. 1Eii, Fii). In marked contrast, bees treated with 20-E failed to show any evidence of learning during the six conditioning trials (responses to $\mathrm{CS}+, Q=4.167$, $\mathrm{DF}=5, P=0.526$; responses to $\mathrm{CS}-, Q=1.923$, $\mathrm{DF}=5, P=$ 0.860 ) (Fig. 1Gi) and they failed to discriminate in their responses between $\mathrm{CS}+$ and $\mathrm{CS}-$. In the retention test, significantly more 20-E-treated bees responded to $\mathrm{CS}+$ than to $\mathrm{CS}-(P=0.031)$ (Fig. 1Gii), but the percentage of bees displaying conditioned responses overall remained very low. Difference scores used to compare learning levels across the three groups revealed no significant differences between vehicle-treated bees and controls (Fig. 1Hi,ii). However, a significant difference was identified between the difference scores recorded for vehicle- and 20-E-treated bees (trial $4, P=0.038$ ) (Fig. 1Hi), and between scores recorded for controls vs. 20 -E-treated bees (trial $4, P=0.014$; trial $6, P=0.035$ ). The difference scores recorded in the retention test for control bees and 

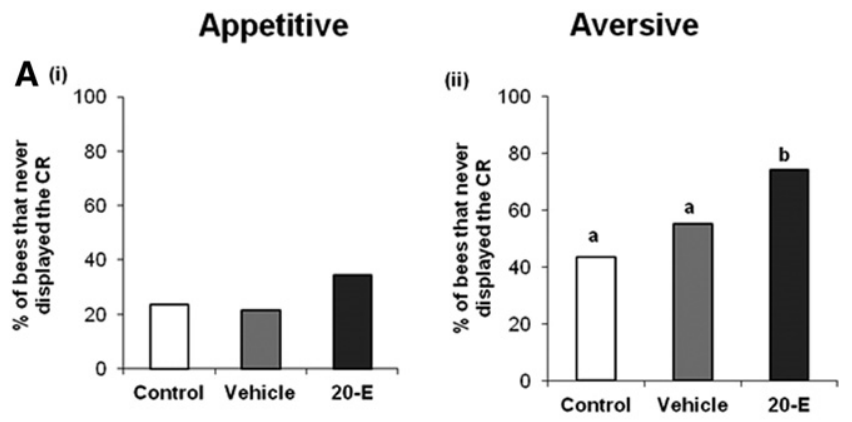

B (i)

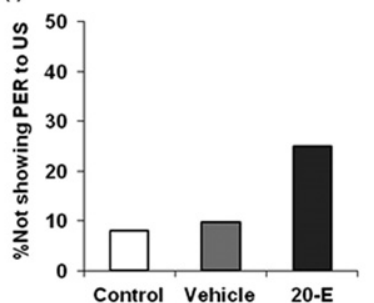

(ii)

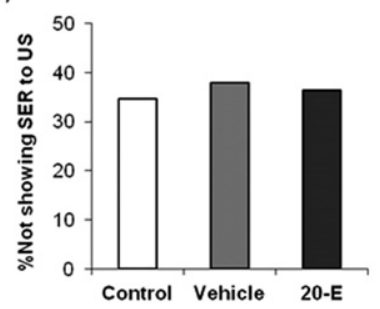

Figure 2. Percentages of bees that failed to respond. $(A)$ The percentage of bees that showed no response to CS + throughout conditioning and in the retention test (proboscis extension response [PER] [Ai] and sting extension response [SER] [Aii]). (B) The percentage of bees excluded because they failed to respond to the unconditioned stimulus (reflexive proboscis extension $[B i]$ and reflexive sting extension [Bii]). Bars with a different letter differ significantly from each other.

20-E-treated bees were also close to being statistically significant $(P=0.053)$ (Fig. 1Hii)

\section{Shock sensitivity is not affected by $20-\mathrm{E}$}

A significantly higher percentage of bees treated with 20-E failed to display conditioned responses during conditioning, and in the retention test, than control bees or bees treated with vehicle (lreg, main effect, $P<0.001$; control $P<0.001$; vehicle only $P<$ 0.001) (Fig. 2Aii). The percentage of bees excluded from aversive conditioning because of failure to respond with sting extension to electric shock (US), however, was similar in all the three treatment groups (Fig. 2Bii). Analysis of shock-sensitivity scores confirmed that 20-E does not alter sensitivity to shock stimuli (Fig. $3 \mathrm{~A}-\mathrm{E})$; in all groups, the proportion of bees responding with reflexive sting extension to electric shock increased significantly as the stimulus intensity was increased (control, $Q=94.070$, $\mathrm{DF}=5, P<0.001$ [Fig. 3A]; vehicle, $Q=74.559, \mathrm{DF}=5, P<$ 0.001 [Fig. 3B]; 20-E, $Q=88.478, \mathrm{DF}=5, P<0.001$ [Fig. 3C]), and significantly fewer bees responded with sting extension to placement alone than to stimulation with either a 4 -V shock (control, $P<0.001$; vehicle only, $P=0.001 ; 20-\mathrm{E}, P<0.001$ ), or $8-\mathrm{V}$ shock $(P<0.001$ for all treatments) (Fig. 3A-C). There were also no significant differences between the percentage of response to each shock stimulus minus the percentage of response to the subsequent placement trial (difference scores) (Fig. 3D), or mean shock scores (Fig. 3E), calculated for each treatment group. Motor activity also appeared to be unaffected by steroid treatment as no significant differences in locomotor activity could be identified between treatment groups (Fig. 3F).

\section{0-E alters the expression of amine-receptor genes}

Transcript levels for the dopamine receptor genes, Amdop1, Amdop2, and Amdop3, the octopamine receptor gene, Amoa1, and the putative dopamine/ecdysone receptor gene, Amgpcr19, in mushroom body intrinsic neurons (Kenyon cells) were compared in control bees and in foragers treated with 20-E (Fig. 4A). While steroid treatment had no significant effect on levels of expression detected for Amdop1, Amdop3, or Amoa1 (Fig. 4ii,iv,v) or the housekeeper gene, $18 \mathrm{~S}$ (Fig. 4Ai), levels of Amdop2 transcript were found to be significantly higher in steroid-treated bees than in controls (Fig. 4iii), whereas levels of Amgpcr19 transcript were significantly lower (Fig. 4vi) in steroid-treated bees than in controls. As aversive learning has been shown to be inhibited in young bees by queen mandibular pheromone (QMP) (Vergoz et al. 2007b), we examined the effects of this pheromone on Amgpcr19 expression in the brains of young (2-d-old) worker bees. While levels of expression of the reference gene $18 \mathrm{~S}$ did not vary between bees reared in the presence or absence of QMP (Fig. 4Bi), in one of three groups tested, Amgpcr19 transcript levels were reduced significantly by QMP (experiment $1, t=-2.84, P=$ $0,022, \mathrm{DF}=8$ ) (Fig. 4Bii).

\section{Amgpcr19 is highly expressed in bees displaying strong aversive learning}

Comparing levels of Amgpcr19 expression in the brains of good and poor learners revealed several interesting and complementary trends. Proportions of good and poor learners were similar across the three independent experiments used to examine appetitive learning (Fig. 5A), and also across the three experiments used to examine aversive learning (Fig. 5D). Levels of expression of the housekeeper gene $18 S$ in the brains of appetitive learners and poor/nonlearners were not significantly different (experiment 1 , $t=-0.13, P=0.901$; experiment $2, t=-0.89, P=0.383$; experiment $3, t=0.19, P=0.854 ; \mathrm{DF}=18$ for all) (Fig. $5 \mathrm{~B}$ ), nor in the brains of aversive learners and nonlearners (experiment $1, t=$ $0.89, P=0.385$; experiment $2, t=-0.07, P=0.945$; experiment $3, t=-0.67, P=0.513 ; \mathrm{DF}=18$ for all) (Fig. 5E). However, levels of mRNA transcript for Amgpcr19 were significantly lower in the brains of excellent appetitive learners compared with those of poor/nonlearners in the first appetitive learning experiment $(t=-2.92, P=0.009, \mathrm{DF}=18)$ (Fig. 5C). The same trend was evident in experiment $2(t=-1.83, P=0.084, \mathrm{DF}=18)$, but in experiment 3 no difference in Amgpcr 19 transcript levels was apparent in excellent vs. poor appetitive learners $(t=-0.59, P=0.565, \mathrm{DF}=$ 18) (Fig. 5C). Interestingly, in the first of the three aversive learning experiments (Fig. 5F), levels of Amgpcr19 mRNA were significantly higher in the brains of learners than in those of nonlearners $(t=$ $2.22, P=0.040, \mathrm{DF}=18)$, a trend strongly reflected also in experiment $3(t=2.09, P=0.055, \mathrm{DF}=18)$. In experiment 2 , there was no difference in expression of Amgpcr19 mRNA between the two groups $(t=-1.15, P=0.265, \mathrm{DF}=18)$ (Fig. 5F).

Comparison of levels of expression of the remaining amine-receptor genes revealed two further differences between learners and nonlearners. Levels of Amdop3 mRNA were significantly higher in the brains of aversive learners than in those of nonlearners in one of the three independent experiments used to examine aversive learners (experiment $1, t=2.57, P=0.019$, $\mathrm{DF}=18$ ) (Fig. 6Cii), and levels of Amoa1 transcript were higher also in learners than in nonlearners in this experiment $(t=-3.39, P=0.003, \mathrm{DF}=18)$ (Fig. 6Dii).

\section{Aversive learning performance is poor in young (2- to 4-d-old) adult worker bees}

Several studies have shown that hemolymph ecdysteroid titers rise to peak levels $\sim 2 \mathrm{~d}$ after adult emergence (Hartfelder et al. 2002; Amdam et al. 2010), then decline to low levels in foragers (Robinson et al. 1991). As exogenously applied 20-E impaired 

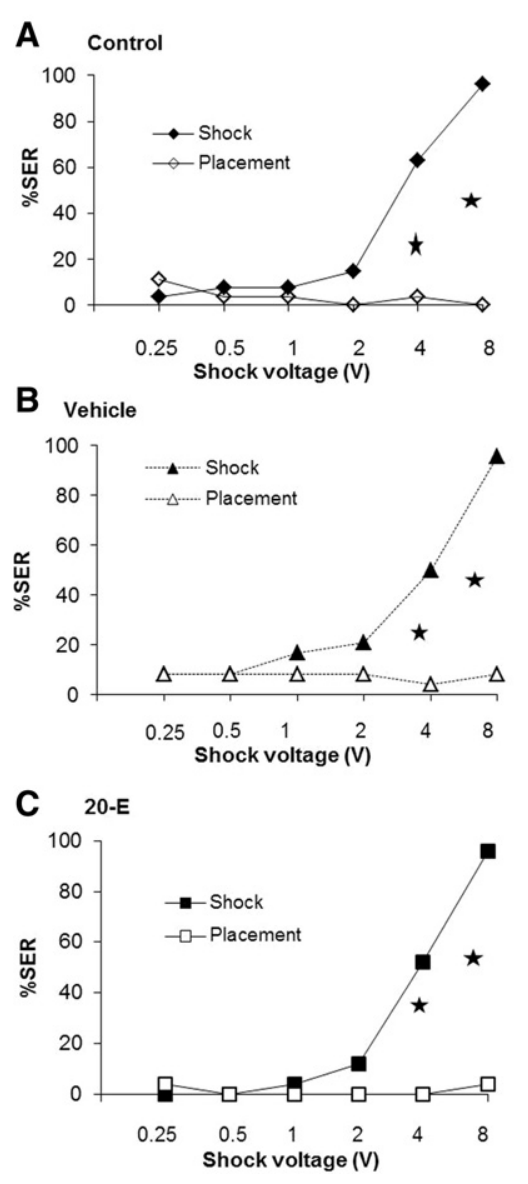

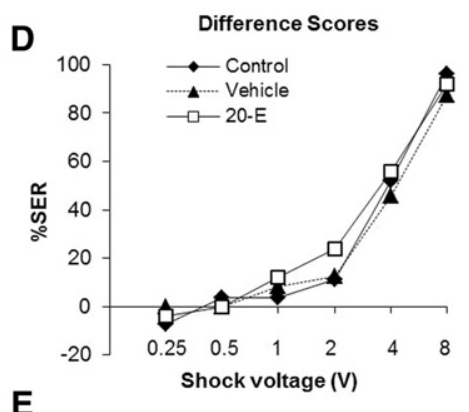

E
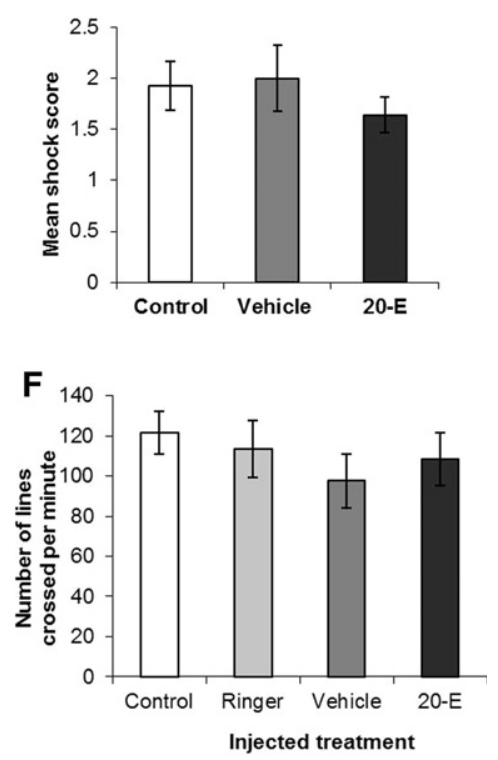

Figure 3. Electric shock sensitivity and locomotor activity. Percentages of controls $(A)$, vehicle-treated bees $(B)$, and 20 -E-treated bees $(C)$ displaying a sting extension response (percentage SER) to electric shocks of increasing voltage (black symbols), compared to percentages of the same bees responding with sting extension to placement trials in which no shock was given (white symbols). $\left({ }^{*}\right)$ Significant difference between response levels to shock and the subsequent placement trial. (D) Difference scores show percentage SER to electric shock minus percentage SER to placement trials. $(E)$ Mean ( \pm SEM) shock scores for the three groups tested. $(A-E)$ Control, $n=27$; vehicle, $n=24$; ecdysone, $n=25$. $(F)$ Locomotor activity. Mean number of lines crossed per minute ( \pm SEM) in bees not injected (control), and bees injected with Ringer, vehicle (Ringer containing 3.2\% ethanol), or 20-E. $n=10$ for each treatment group.

aversive learning in foragers (see above), we were interested to examine aversive learning performance in bees at a time when endogenous 20-E levels are reported to be naturally high. We found that aversive learning performance in 2-d-old bees was extremely poor (Fig. 7A). Although there was significant variation in the level of responses to CS+ over the six conditioning trials $(Q=$ 14.907, $\mathrm{DF}=5, P=0.011$ ) (Fig. 7Ai), the percentage of 2-d-olds displaying the conditioned response in the last conditioning trial $(11.6 \%)$ was below that recorded in the first trial (15\%). Moreover, while responses of 2-d-old bees to the nonreinforced odor (CS-) declined from $21.6 \%$ in the first trial to $1.6 \%$ in the fourth trial $(Q=27.77, \mathrm{DF}=5, P=0.0001)$, there was no significant difference between the level of responses to CS + and CS - in the retention tests $(P=0.125)$ (Fig. 7Aii). By $3 \mathrm{~d}$ of age, bees showed stronger discrimination between the two odors (CS+ and CS - ). Although the percentage of 3-d-old bees exhibiting sting extension responses to $\mathrm{CS}+$ showed little change over the six conditioning trials $(Q=8.276, \mathrm{DF}=5, P=0.142)$ (Fig. 7Bi), there was a significant decline in responses to $C S-(Q=23.585, D F=5$, $P<0.0001)$ and 3 -d-old bees responded more to CS+ than to $\mathrm{CS}-$ in the retention tests $(P=0.0001)$ (Fig. 7Bii). Aversive learn- ing performance in 4-d-old bees (Fig. 7Ci,ii) was similar to that observed in bees at $3 \mathrm{~d}$ of age and, as shown elsewhere in 6-d-olds (Vergoz et al. 2007b), aversive learning and short-term memory recall could be blocked in 4 -d-old bees by exposing bees to queen mandibular pheromone (Fig. 7Di,ii).

\section{Discussion}

Effects of 20-E on associative olfactory conditioning of forager bees were found to be highly selective. Injection of this steroid hormone prior to conditioning blocked changes in responsiveness toward odors associated with punishment (aversive learning), but had little, if any, effect on associative learning of the same odors if they were associated with a food reward (appetitive learning). Steroid-induced impairment of aversive learning was particularly prominent during the conditioning period. While control bees and vehicle-injected bees learned to respond differentially to the reinforced odor (CS+) and nonreinforced odor (CS - ), this was not the case in bees treated with 20-E (Fig. 1F,G). Moreover, the proportion of bees that failed to respond to CS+ during aversive conditioning was significantly higher in bees treated with 20 -E than in control bees or bees treated with vehicle alone (Fig. 2A). This, together with the poor aversive learning performance observed in bees 2-3 d after adult emergence, is consistent with the hypothesis that aversive learning is impaired when 20-E levels are high. Interestingly, in forager bees, effects of 20-E on aversive learning were accompanied by lowered levels of expression in mushroom bodies of the brain of the putative dopamine/ecdysone receptor gene, Amgpcr19. A similar response could be induced in some (but not all) 2-d-olds by exposing the young bees to queen mandibular pheromone, a pheromone shown here and elsewhere to reduce aversive learning performance in young worker bees (Vergoz et al. 2007b). As both 20-E and QMP impair aversive learning performance in young bees, it is interesting to note that both were found to reduce expression levels of Amgpcr19, the honeybee ortholog of $D m D o p E c R$, a gene that codes for a dopamine/ecdysone responsive receptor in Drosophila (Srivastava et al. 2005).

Impairments of aversive learning observed in this study could not be attributed to shifts in shock sensitivity. However, learning performance was affected in part by the vehicle used in this study to deliver 20-E. Earlier reports have shown that bees fed ethanol show impairments in both appetitive learning (Mustard et al. 2008) and locomotor activity (Abramson et al. 2000; Bozic et al. 2006; Maze et al. 2006). Using harnessed bees, for example, Mustard et al. (2008) found that 5\% ethanol reduced both the rate of acquisition of associative olfactory memories and the asymptotic strength of the association, effects that were apparent to some degree also in the current investigation. However, we were encouraged by a pilot study in which vehicle alone 
A (i)
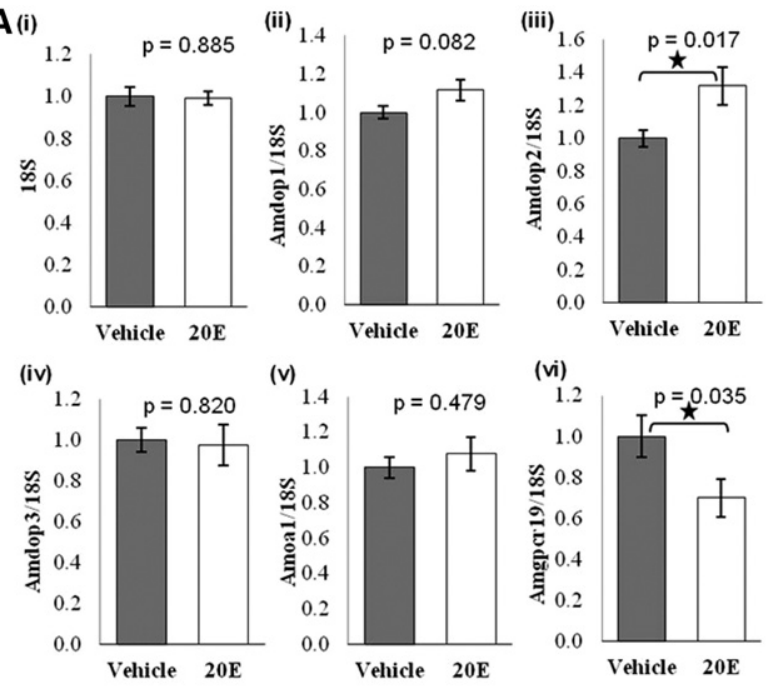

(v) $1.4, p=0.479$

(vi)

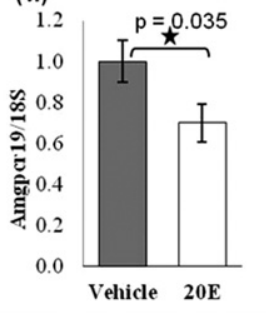

$\mathbf{B}_{(\mathbf{i})}$
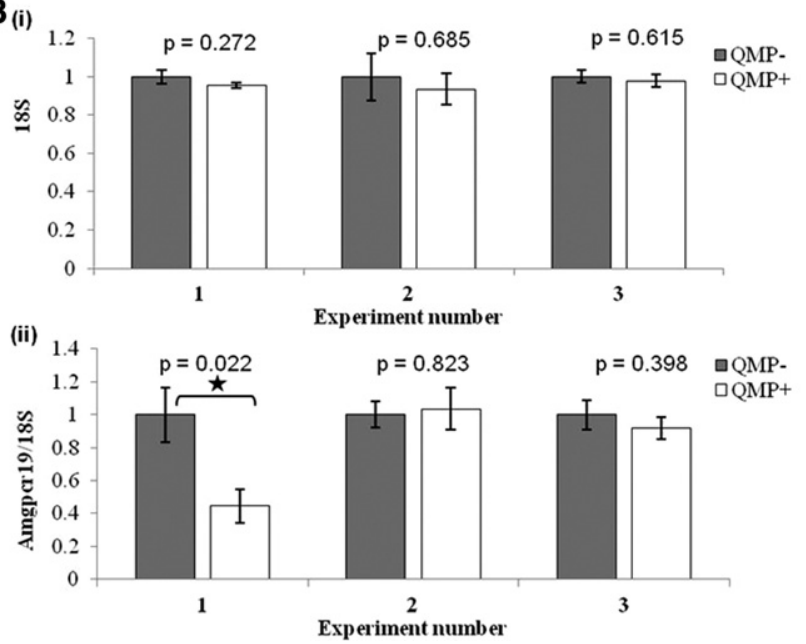

Figure 4. Effects of 20-E and QMP on transcript levels of genes of interest. $(A)$ Effects of 20-E on transcript abundance in the mushroom bodies of forager bees. Mean transcript levels ( \pm SEM) detected in three independent experiments: 18S (Ai), Amdop1 (Aii), Amdop2 (Aiii), Amdop3 (Aiv), Amoa1 (Av), Amgpcr19 (Avi). $n=5$ for each group. Data are normalized to transcript levels detected in controls. $(B)$ Effects of QMP on levels of expression of Amgpcr19 in the brains of 2-d-old bees. Mean transcript levels $( \pm$ SEM) detected in three independent experiments. Experiments 1 and $2, n=5$ samples of five brains each. Experiment 3, $n=10$ individual brains. (BI) 18S. (Bii) Amgpcr19. P-values from pairwise comparisons are shown. $\left({ }^{*}\right)$ Significant differences between groups.

(containing 3.2\% ethanol) had no significant impact on locomotor activity and, in addition, by subsequent experiments showing that appetitive learning remained strong after treatment with vehicle alone. In contrast to appetitive learning, the acquisition of aversive memories was clearly inhibited by vehicle treatment and, probably, by the low levels of ethanol that it contained. Nonetheless, effects of $20-\mathrm{E}$, over and above those of vehicle alone, were striking.

Treatments with 20-E may interfere with dopamine signaling in the bee. Dopamine release at the level of the mushroom bodies of the brain has been shown to be necessary for the formation of aversive olfactory memories (e.g., Schwärzel et al. 2003; Riemensperger et al. 2005; Schroll et al. 2006; Vergoz et al. 2007a). In the present study we found that 20-E treatment enhances the expression of the dopamine receptor gene, Amdop2, in the mushroom bodies of the brain. Interestingly, the Drosophila ortholog of this gene, $D A M B$, which is highly expressed in the mushroom bodies of the fly (Han et al. 1996), has recently been implicated in forgetting (Berry et al. 2012). However, dopamine signaling, at least in flies, is involved not only in aversive learning, but also in the formation of appetitive olfactory memories (Kim et al. 2007; Selcho et al. 2009; Burke et al. 2012; Liu et al. 2012). The selectivity of the effects of 20 -E observed in this study are therefore intriguing. One

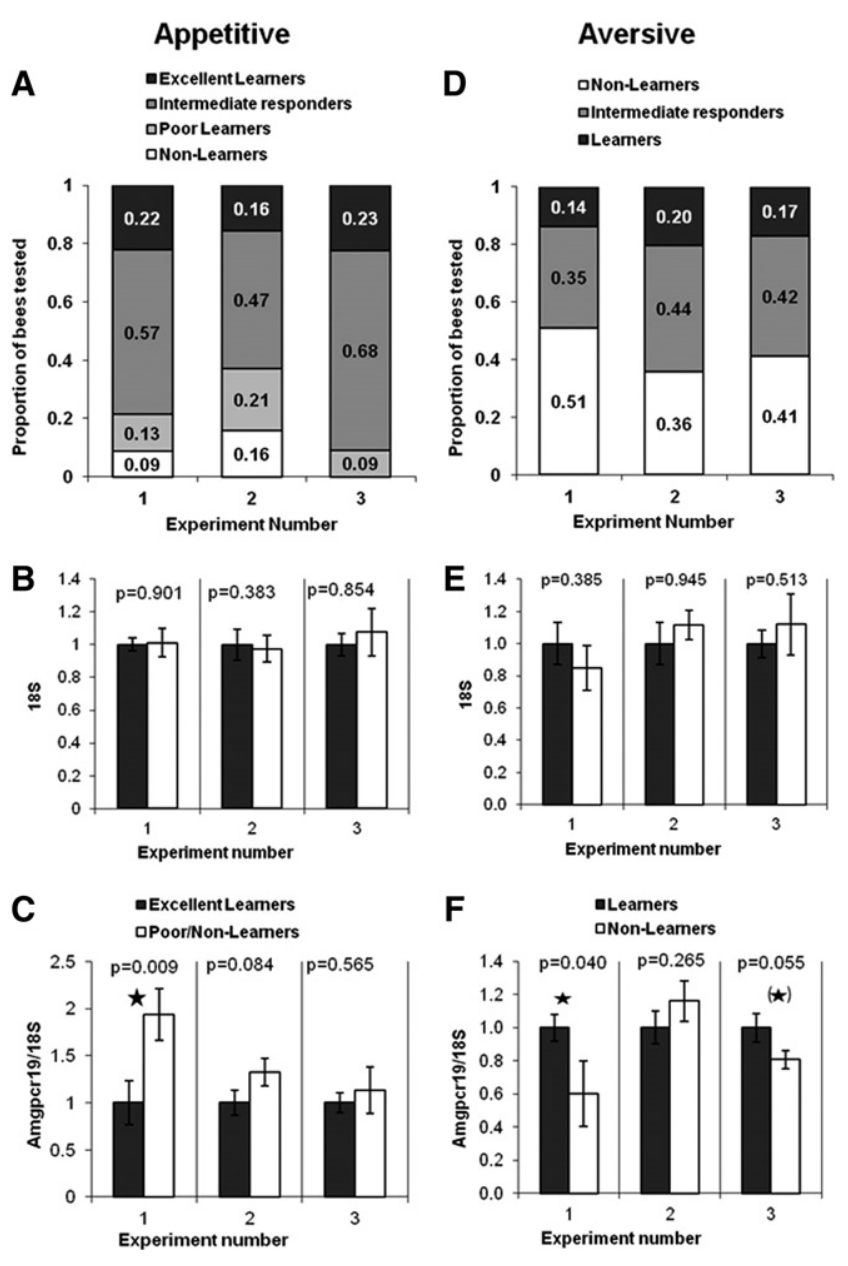

Figure 5. Proportions of good vs. poor learners and relative transcript abundances of genes of interest. (A) Proportions of foragers classified as "excellent learners," "intermediate responders," "poor learners," and "nonlearners" in three independent appetitive learning experiments. Experiment 1, $n=104$; experiment 2, $n=70$; experiment $3, n=111$. (B) Mean levels of mRNA transcript ( \pm SEM) for $18 \mathrm{~S}$ detected in the brains of 10 foragers classified as excellent learners (black bars) vs. 10 foragers classified as poor/nonlearners (white bars). (C) Mean levels of mRNA transcript $( \pm$ SEM) for the putative dopamine/ecdysone receptor gene, Amgpcr19, normalized to $18 \mathrm{~S}$ and expressed relative to levels detected in the brains of bees classified as "excellent learners." (D) Proportions of forager bees classified as "learners," "intermediate responders," and "nonlearners" in three independent aversive learning experiments. Experiment 1, $n=51$; experiment 2, $n=59$; experiment 3, $n=78$. (E) Mean levels of mRNA transcript ( \pm SEM) for 185 detected in the brains of 10 foragers classified as learners (black bars) vs. 10 foragers classified as nonlearners (white bars). $(F)$ Mean levels of mRNA transcript $( \pm$ SEM) for the putative dopamine/ecdysone receptor gene, Amgpcr19, normalized to $18 \mathrm{~S}$ and expressed relative to levels detected in the brains of bees classified as "learners." $P$-values for $t$-tests between groups within each experiment are shown. (*) Significant differences between groups within an experiment. 
Appetitive

A (i)

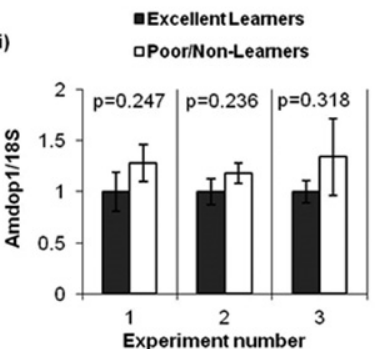

B (i)

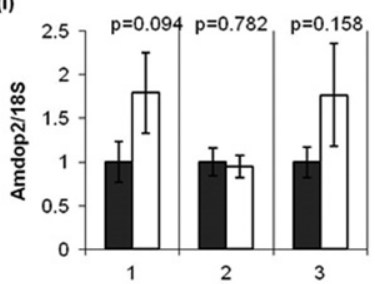

C (i)

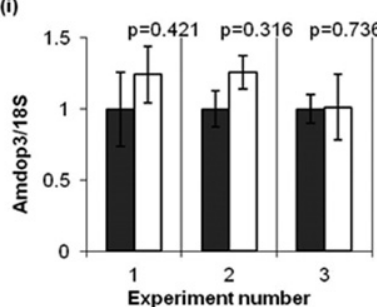

(i)

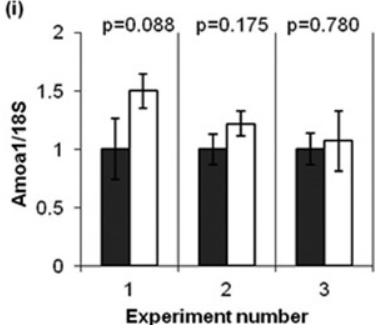

Aversive

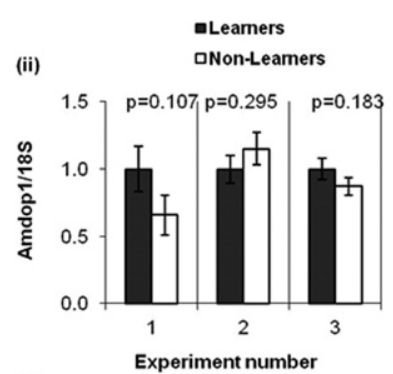

(ii)
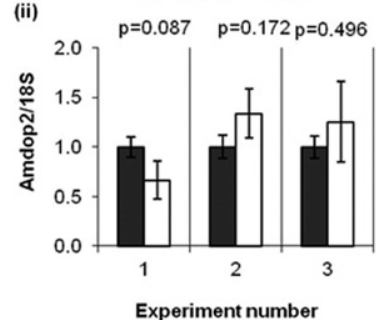

(ii) $1.5 \quad \mathrm{p}=0.019 \quad \mathrm{p}=0.491 \quad \mathrm{p}=0.489$

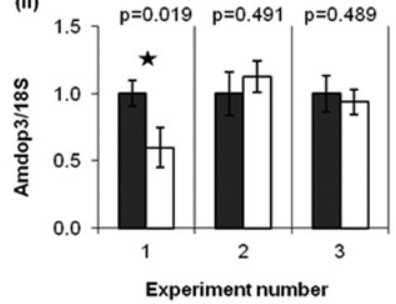

(ii)

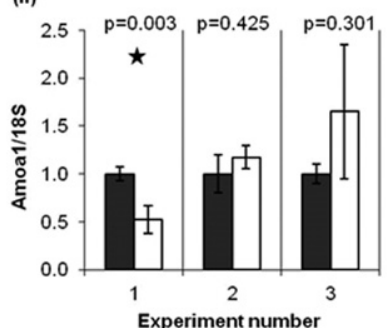

Figure 6. Relative transcript levels of genes of interest in the brains of good and poor learners. ( $A i-D I$ ) Mean transcript levels ( \pm SEM) detected in the brains of bees conditioned using an appetitive conditioning paradigm and identified either as excellent learners or poor/nonlearners. (Aii-Dii) Mean transcript levels ( \pm SEM) detected in the brains of bees conditioned using an aversive conditioning paradigm and identified either as learners or nonlearners. The genes of interest examined were the honeybee dopamine receptor genes, Amdop1 (Ai, ii), Amdop2 (Bi, ii), and Amdop3 $(\mathrm{Ci}, \mathrm{ii})$, and the octopamine receptor, Amoa1 (Di, ii). Mean levels of mRNA transcript ( \pm SEM) are normalized to 185 and expressed relative to levels detected in the brains of bees classified as (excellent) learners. $P$-values for $t$-tests between groups within each experiment are shown. (*) Significant differences between groups within an experiment.

critical difference identified at the cellular level between the formation of aversive memories and short-term appetitive memories in flies is that appetitive memory formation is supported not only by dopamine but also by octopamine (Schwärzel et al. 2003; Schroll et al. 2006; Burke et al. 2012). Octopamine plays a central role also in the formation of appetitive memories in bees (Hammer 1993, 1997; Hammer and Menzel 1998) and growing evidence suggests interplay between modulatory pathways that signal punishment and reward. In honeybees, for example, treatments that increase octopamine levels are reported to impair the

formation of aversive memories (Agarwal et al. 2011). In moths and flies (Granger et al. 1996; Gruntenko et al. 2005) there is evidence of feedback regulation between levels of ecdysteroids and dopamine, but changes in ecdysteroid levels, at least in Drosophila, are reported to have no effect on levels of the biogenic amine, octopamine (Gruntenko et al. 2007). Differential effects of 20-E on pathways that modulate learning circuits of the brain might help explain the differential effects of 20 -E on learning behavior observed in this study.

Predicted properties of the receptor encoded by Amgpcr19 (Apis mellifera G-Protein-Coupled Receptor, \#19) (Hauser et al. 2006) suggest a mechanism for interplay between dopamineand ecdysteroid-signaling pathways in the bee. AmGPCR19 is the honeybee ortholog of DmDopEcR, a novel receptor identified in Drosophila that is responsive not only to ecdysteroids, but also to dopamine (Srivastava et al. 2005). Amgpcr19 tended to be expressed at relatively high levels in the brains of bees that performed well in aversive learning assays, but expressed in relatively low levels in the brains of bees displaying strong appetitive learning, perhaps suggesting that AmGPCR19 functions at the interface between pathways signaling punishment and reward. Based on these results, one might predict that bees would be unlikely to perform equally well in appetitive vs. aversive learning. Consistent with this hypothesis, Vergoz et al. (2007a) report that when bees were conditioned to associate one odor with positive reinforcement and a second odor with negative reinforcement, only $14 \%$ of the bees mastered both associations, a hint perhaps of a genetic trade-off between high aptitudes for aversive vs. appetitive learning (see also Mery and Kawecki 2003; Mery et al. 2007).

It is well established in bees, as in other insects, that mushroom bodies play a central role in the formation of associative olfactory memories (see above). In adult worker honeybees, genes for ecdysteroid signaling have been found to be highly expressed in this region of the brain (Paul et al. 2005, 2006; Velarde et al. 2006, 2009; Yamazaki et al. 2006, 2011; Takeuchi et al. 2007), and marked changes in gene expression in mushroom body intrinsic neurons have been described in response to 20-E (Velarde et al. 2009). Interestingly, Velarde et al. (2009) also showed that juvenile hormone $(\mathrm{JH})$ modulates the expression of ecdysteroidresponsive receptor genes in the mushroom bodies of adult honeybees, an observation that may be of relevance to findings in this study. Differences in levels of Amgpcr19 expression between learners and nonlearners, for example, were most pronounced in experiments undertaken during the winter months (experiment 1 for both aversive and appetitive learning). At this time also, significant differences between levels of Amdop3 and Amoa1 in the brains of learners vs. nonlearners were identified in bees conditioned using an aversive conditioning protocol. Winter bees are reported to have lower hemolymph titers of $\mathrm{JH}$ than those of summer bees (Fluri et al. 1982; Huang and Robinson 1995), a factor that may have contributed to differences in receptor gene expression between learners and nonlearners being more prominent at this time. It is interesting to note in this regard also that the low levels of $\mathrm{JH}$ found in young worker bees compared with adults (Robinson et al. 1991) may be caused by queen mandibular pheromone (Kaatz et al. 1992; Pankiw et al. 1998), a pheromone that inhibits aversive learning in young worker bees (Vergoz et al. 2007b, and present study) and which has a significant impact on the expression of genes in the brain (Grozinger et al. 2003; Beggs et al. 2007), including levels of expression of Amgpcr19 (present investigation). As gene expression in the mushroom bodies of the brain is affected by foraging experience (Lutz et al. 2011), potential differences in the age and experience of the foragers used in this study may also have contributed to the intertrial variability observed in our analysis of receptor gene expression in learner vs. nonlearner bees. 
A (i)

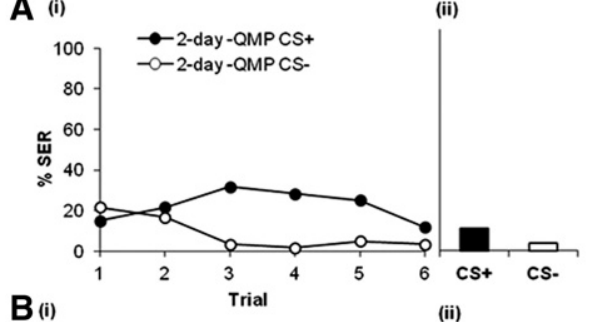

$\mathbf{B}$ (i)

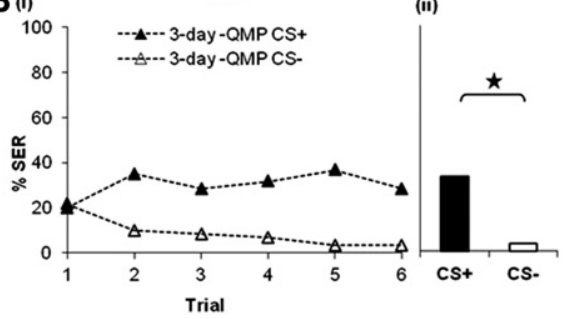

C (i)

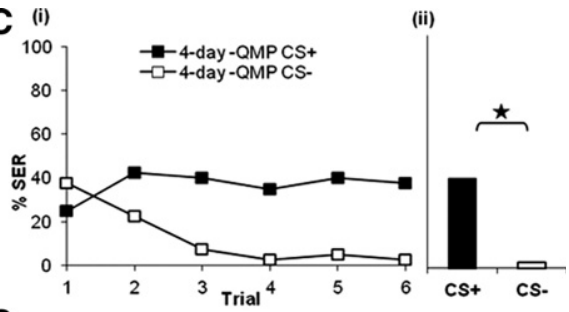

$\mathbf{D}_{\text {(i) }}$

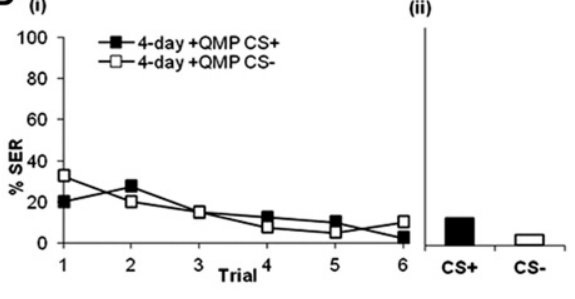

Figure 7. Aversive learning performance is poor at a time when endogenous ecdysteroid titers are high. $(A-D)$ Aversive learning performance in young worker bees, 2-4 d after adult emergence $(A-$ $C$, respectively) and in 4 -d-old bees treated with queen mandibular pheromone $(D)$. (Ai-Di) Acquisition curves show the percentage of bees displaying a sting extension in response to an odor $(\mathrm{CS}+)$ paired with electric shock (black symbols), and to a second odor (CS - ) that was not reinforced (white symbols). (Aii-Dii) Percentage of bees responding to the reinforced odor (CS+, black bars) and the nonreinforced odor (CS - , white bars) $1 \mathrm{~h}$ after the last conditioning trial (retention test [RT]). $\left(^{*}\right)$ Significant differences between the level of responses to CS + and $\mathrm{CS}-$.

In Drosophila, 20-E levels have been found to be elevated after courtship conditioning in which male flies that are only able to court unreceptive, nonvirgin females suppress their courtship behavior, even toward receptive virgin females (Ishimoto et al. 2009). Interestingly, the effects of exogenous administration of 20-E on long-term memory (LTM) in the fly depended on its time of administration; 20-E present during the training period enhanced LTM formation, whereas in flies in which 20-E was administered after conditioning and before the memory test, LTM was impaired (Ishimoto et al. 2009). While it is difficult to compare aversive learning in honeybees directly with courtship conditioning in the fly, the results of the present study show that in bees, as in flies, learning is able to be modulated by ecdysteroids. In addition, our results suggest that AmGPCR19, the honeybee counterpart of a dopamine/ecdysone responsive receptor in the fly $(D m D o p E c R)$, may be intimately involved in events that lead to 20-E modulation of aversive learning behavior in the bee. This is of particular interest here because functional properties of the Drosophila ortholog of AmGPCR19 (DmDopEcR) (Srivastava et al. 2005) suggest a mechanism whereby ecdysteroids could modulate dopamine signaling in the brain. It will be important to confirm that AmGPCR19 shares the same properties and to clarify the role that this novel receptor plays in associative olfactory learning and memory in the honeybee.

\section{Materials and Methods}

\section{Animals}

Honeybees (Apis mellifera L.) were collected from hives located at the Department of Zoology, University of Otago (Dunedin, New Zealand). To collect young bees of known age, newly emerged adults were removed from brood frames and reared in incubators as described in detail elsewhere (Vergoz et al. 2007b). The majority of foragers used in this study were pollen foragers. These bees were collected at the hive entrance and identified by the pollen grains attached to their legs. Nectar foragers were collected while feeding at artificial feeders placed $5-15 \mathrm{~m}$ from the hives but were included in only one of the experiments described below.

\section{0-Hydroxyecdysone (20-E) treatment}

To prepare 20-E for injection, stock solution $(10 \mu \mathrm{M} 20-\mathrm{E}$, Fluka) was dissolved in $100 \%$ ethanol to prevent crystallization of the steroid and then diluted in Bee Ringer containing $130 \mathrm{mM} \mathrm{NaCl}, 6 \mathrm{mM}$ $\mathrm{KCl}, 4 \mathrm{mM} \mathrm{MgCl}, 5 \mathrm{mM} \mathrm{CaCl}, 160 \mathrm{mM}$ sucrose, $25 \mathrm{mM}$ glucose, and $10 \mathrm{mM}$ HEPES (pH 6.7, $500 \mathrm{mOsmol}$ ) to give a final concentration of $150 \mathrm{pg} / \mu \mathrm{L} 20$ $\mathrm{E}$ in Ringer containing 3.2\% ethanol. Treatments with 20-E were carried out on foragers. Forager bees were cold-immobilized, then assigned to one of three treatment groups; bees receiving no injection (Controls), bees injected with 2 $\mu \mathrm{L}$ Bee Ringer containing 3.2\% ethanol (Vehicle), and bees injected with $2 \mu \mathrm{L}$ vehicle containing steroid (20-E). Injections were performed using a $5-\mu \mathrm{L}$ Hamilton syringe (900 series, Sigma-Aldrich) inserted into the hemocoel through the abdominal body wall between the fifth and sixth tergal plates. Bees that showed obvious hemolymph leakage as a result of the injection procedure were excluded $(<1 \%$ of bees injected). The ecdysteroid titer in 20-d-old bees is reported to be $\sim 5 \mathrm{pg} / \mu \mathrm{L}$ (Hartfelder et al. 2002). Forager bees were injected with 300-pg 20 -E in a $2-\mu \mathrm{L}$ injection volume. As adult worker bees have $\sim 15 \mu \mathrm{L}$ of hemolymph (Crailsheim 1985), the final concentration in the bee was estimated to be $\sim 20 \mathrm{pg}$ $20-\mathrm{E} / \mu \mathrm{L}$, similar to peak ecdysteroid levels reported in the first $2-3 \mathrm{~d}$ of adult life $(\sim 13 \mathrm{pg} / \mu \mathrm{L})$ (Hartfelder et al. 2002; see also Amdam et al. 2004, 2010). Injections were carried out 1-1.5 h before the conditioning trials, which took $2 \mathrm{~h}$ to complete. To examine effects of 20-E on levels of receptor gene transcript in mushroom bodies of the brain (see below), bees were treated with steroid $3 \mathrm{~h}$ prior to removal of brain tissue for analysis.

\section{Associative olfactory conditioning}

Behavioral experiments were carried out between 10 a.m. and 2 p.m. in an attempt to avoid diel changes in brain amine levels that could potentially influence the learning performance of the bees (Purnell et al. 2000). Bees in the three treatment groups described above (control, vehicle, 20-E) were restrained in individual harnesses as described elsewhere (Vergoz et al. 2007a) and then left for $1-1.5 \mathrm{~h}$ to adjust to their environment. Bees used to examine the effects of 20-E on aversive learning performance were fed $30 \%$ sucrose solution during this period. However, as appetitive conditioning in insects depends highly on hunger-induced motivation (Friedrich et al. 2004; Krashes et al. 2009), bees used to examine effects of 20 -E on appetitive learning were not fed at this time. Aversive learning was examined also in bees $2-4 \mathrm{~d}$ after adult emergence when steroid levels in the hemolymph are reported to be high (Hartfelder et al. 2002; Amdam et al. 2010).

\section{Conditioning protocol for appetitive learning}

Olfactory conditioning of the proboscis extension reflex (Kuwabara 1957; Takeda 1961; Bitterman et al. 1983) was used to examine appetitive learning performance in foragers. Groups of 20 bees at a time were collected and, prior to conditioning, divided into the three treatment groups. In total, 103 foragers were examined: controls $(n=34)$, vehicle-treated bees $(n=37)$, and bees treated with $20-\mathrm{E}(n=32)$. A differential conditioning proto$\mathrm{col}$ was used. Bees were conditioned to differentiate between an odor (odor A) paired with a food reward $(\mathrm{CS}+)$, and an odor (odor $\mathrm{B}$ ) that was not reinforced ( $\mathrm{CS}-$ ). Odors were delivered to the bee by placing a small piece of filter paper with $5 \mu \mathrm{L}$ of pure odorant into a $20-\mathrm{mL}$ syringe, and using the syringe to deliver 
puffs of odor-filled air across the antennae of the bee. Each odor was presented to the bee for $5 \mathrm{sec}$. Two seconds after the onset of odor $\mathrm{A}(\mathrm{CS}+)$, reflexive proboscis extension was elicited by stimulating the antennae of the bee with a 30\% sucrose solution (the unconditioned stimulus, US) and the bee was allowed to feed briefly from the sucrose droplet. Bees that failed to display the proboscis extension reflex in response to sucrose stimulation of the antennae were excluded. Odor B was presented to the bee in a similar manner but was not reinforced with a sucrose reward. The floral odors eugenol and 2-hexanol were used in this study. For half of the bees tested, eugenol was the reinforced odor, while for the remaining bees the odor reinforced was 2-hexanol. Each odor was presented to the bee six times in a pseudorandom sequence (ABBABAABABBA) beginning, in a balanced way, with either odor A or B. A 10-min interval was included between each conditioning trial, and each bee received 12 conditioning trials in total. During each trial, a record was taken of whether or not the bee responded to the odor with proboscis extension (prior to receiving the reinforcer in the case of odor A). One hour after the last conditioning trial a retention test was performed in which both odors were presented without reinforcement. Again, the order of presentation of the two odors (A and B) was randomized, and the proportion of bees responding with proboscis extension to each odor was recorded. Throughout conditioning and in all subsequent trials, an air extractor was used to remove odorants from the training area. Data obtained from bees subjected to appetitive conditioning were analyzed as described below for aversive conditioning.

\section{Conditioning protocol used to demonstrate aversive learning}

Aversive conditioning was performed using the protocol established by Vergoz et al. (2007a) using olfactory conditioning of the sting extension reflex. Briefly, reflexive sting extension was elicited by delivering a 2-sec electric shock $(60 \mathrm{~Hz}, 7.5 \mathrm{~V})$ to the thorax of the bee using a Grass SD9 stimulator. Bees were conditioned using a differential conditioning paradigm similar to that described above in which one odor (CS+) was paired with reinforcement (in this case, electric shock), while a second odor $(\mathrm{CS}-)$ was not reinforced. Bees that learned to associate the reinforced odor with punishment began extending their sting beyond the carapace in response to the odor alone. In the case of foragers, groups of 20 bees at a time were collected and divided into the three treatment groups (control, vehicle-treated, 20-E) prior to conditioning. In total, 193 forager bees were examined: controls $(n=85)$, vehicle $(n=54), 20$-E $(n=54)$.

In addition, the effect of queen mandibular pheromone on aversive learning was examined in young bees $(2,3$, and $4 \mathrm{~d}$ after adult emergence) with 60 bees in each age group. Queen mandibular pheromone (QMP) is a pheromone that has been shown elsewhere to block aversive learning in young worker bees (Vergoz et al. 2007b). To confirm these effects and to examine effects of the pheromone on Amgpcr19 expression, newly emerged adults were collected from a brood frame and placed in plastic cages $(8 \mathrm{~cm} \times 3.5 \mathrm{~cm} \times 1 \mathrm{~cm}, 10$ bees per cage). Cages of bees were kept in an incubator to maintain constant temperature $\left(\sim 33^{\circ} \mathrm{C}\right)$, relative humidity $(\sim 65 \%)$, and dark/red-light conditions. Water and food (30\% sucrose solution) were available ad libitum. Bees were maintained in the cages until they were 2,3 , or $4 \mathrm{~d}$ old. A strip of synthetic QMP $(\sim 1 \mathrm{~cm}$ in length, $\sim 2.5$ queen equivalents [BeeBoost, PheroTech]) was placed in half of the cages (QMP+ cages). Bees in the remaining cages were not exposed to QMP (QMP - cages).

Data obtained from bees subjected to aversive conditioning or to appetitive conditioning (see above) were analyzed as follows. Within each group, changes in the percentage of bees responding to a given odor over the six conditioning trials were analyzed using Cochran tests for dichotomous data. Differences between responses to CS + and CS - in retention tests were examined using McNemar tests. To compare responses to CS + and CS - between treatment groups, a difference score (percentage response to $\mathrm{CS}+$ minus percentage response to $\mathrm{CS}-$ ) was calculated for each conditioning trial, and for the retention test. Treatment group difference scores were compared using Mann-Whitney tests. We also compared the proportions of bees across all treatment groups that showed no response at all to $\mathrm{CS}+$, as well as the percentages of bees excluded because they failed to respond reflexively to the unconditioned stimulus (sucrose stimulation of the antennae in the case of appetitive conditioning, and electric shock stimulation in the case of aversive conditioning). For comparisons across treatment groups a binary logistic regression analysis (categorical) was performed twice for each type of learning; first with the control group as the reference (main effect), and second with the vehicle group as the reference.

\section{Analysis of effects of 20-E on shock sensitivity}

As shock sensitivity has been shown to vary within worker honeybees depending on caste (Roussel et al. 2009), and as changes in sensitivity to the unconditioned stimulus (electric shock) could potentially contribute to changes in learning performance, we also examined the effects of elevated 20-E levels on shock sensitivity. Forager bees in the three treatment groups (control $n=27$; vehicle $n=24$; 20-E $n=25$ ) were harnessed in the holders used for aversive conditioning and, after a 1-h recovery period, their sensitivity to shocks ranging from $0.25 \mathrm{~V}$ to $8 \mathrm{~V}$ was measured using a protocol similar to that described by Roussel et al. (2009). Each bee received six electric shocks of increasing voltage $(0.25,0.5,1,2,4$, and $8 \mathrm{~V}$ ). "Placement" trials in which bees were placed in the electrical stimulation set-up but no shock was given were interspersed between each shock trial. An intertrial interval of 2 min was used between all trials. A bee's response to each stimulus (shock, or placement) was scored $(0=$ no sting extension, $1=$ sting extension). An overall shock-responsiveness score was calculated for each bee as the sum of all responses made to shocks of all voltages over the six shock trials. Bees that failed to respond with sting extension to a higher subsequent voltage after responding to a lower voltage were excluded (10.2\% of bees tested). Electric shock sensitivity within each treatment group was assessed using Cochran tests and mean shock scores for each treatment group were compared using single-factor ANOVAs. Differences between the proportion of bees within a group responding to shock and to subsequent placement were analyzed using McNemar tests. Difference scores (percentage response to each shock stimulus minus percentage response to the subsequent placement trial) were calculated for each treatment group, and compared using Mann-Whitney tests.

\section{Analysis of effects of 20-E on motor activity}

Changes in motor activity could potentially contribute also to apparent changes in learning behavior. To test for general effects of 20-E on motor activity, a simple locomotion assay was performed. Locomotor activity was examined using 10 pollen foragers from each of four treatment groups; controls (no injection), bees injected with Ringer only (Ringer), bees treated with vehicle only (Vehicle), and steroid-treated bees (20-E). Each group of bees was placed into a plastic cage $(8 \mathrm{~cm} \times 3.5 \mathrm{~cm} \times 1 \mathrm{~cm})$ in a red-illuminated incubator at $30^{\circ} \mathrm{C}-35^{\circ} \mathrm{C}$ for $20 \mathrm{~min}$ to recover from the injection procedure. Each bee was then placed on a vinyl surface warmed to $35^{\circ} \mathrm{C}$, covered with the lid of a Petri dish marked with a $2 \times 2 \mathrm{~cm}$ grid pattern, and given 1 min to adjust to their new surroundings. Locomotor activity was assessed by recording the number of times the thorax of the bee crossed a grid line over a 4-min period. Mean numbers of lines crossed by bees per minute in each treatment group were compared using singlefactor ANOVAs.

\section{Analysis of effects of 20-E on gene transcript levels}

To examine effects of 20-E on the expression of amine-receptor genes that are likely to play a role in associative olfactory learning, calyces of the mushroom bodies from both brain hemispheres were plucked from the brain $(n=5)$, promptly frozen on dry ice, and stored at $-80^{\circ} \mathrm{C}$ until further processing. Brains were 
collected $3 \mathrm{~h}$ after injection of either vehicle alone or 20-E. The 3-h time point was chosen to match the time taken to complete the six conditioning trials in the behavioral assays (described above). Previous studies have identified significant changes in gene expression levels $3 \mathrm{~h}$ after injection of 20-E into the hemolymph of the bee (Velarde et al. 2009). As the studies by Velarde and colleagues also revealed that gene expression levels can be altered by the vehicle used to deliver 20-E, control bees used in the present study for comparison with 20-E-treated bees were treated with vehicle alone. Each tissue sample was homogenized in a $1.5-\mathrm{mL}$ tube using a plastic pestle and $0.5 \mathrm{~mL}$ TRIZOL LS Reagent (Invitrogen). RNA was isolated using PureLink LS Mini Total RNA columns (Invitrogen), and yields quantified using a RiboGreen RNA quantitation assay kit (Invitrogen). Reverse transcriptions were performed using 100-ng total RNA per sample and a Superscript III VILO cDNA synthesis kit (Invitrogen). Gene-specific amplification products were generated using ExpressSYBR GreenER qPCRSuperMix (Invitrogen) and an MX3000P instrument (STRATAGENE). Primer pair sequences, melting products, and reaction efficiencies are shown in Table 1 . Reaction efficiencies were generated using standard curves derived from a serial dilution of pooled cDNA taken from all samples and calculated using the Mx3000P Real-TIME PCR System software (STRATAGENE). All reactions, including no-template controls (NTCs) were performed in triplicate. Expression levels of the honeybee dopamine receptor genes, Amdop1, Amdop2, and Amdop3, the octopamine receptor gene, Amoa1, and the putative amine/ecdysone receptor, Amgpcr19, were calculated using the ddCt method with targetspecific assay efficiencies included. Data were normalized using $18 S$ as a reference gene (see McQuillan et al. 2012). Levels of expression of target genes in the mushroom bodies of control vs. 20 -E-injected bees were compared using paired two-sample $t$-tests with equal variances assumed between groups. For purposes of comparison, mean gene-expression levels are expressed relative to the mean for the control group, which was normalized to 1.0.

\section{Analysis of effects of queen mandibular pheromone on Amgpcr19 expression levels}

Newly emerged bees were reared until $2 \mathrm{~d}$ of age either in the presence (QMP+ cages) or absence (QMP - cages) of QMP as described above for the behavioral QMP-exposure experiment. Three independent experiments were carried out at different times of the year. In the first two trials, pooled brains (five brains per sample, five samples per group) were analyzed. In trial 3 , individual brains (10 per group) were collected and analyzed. Bees were cold-immobilized prior to removing the brain. RNA was extracted from the brain samples and relative abundance of $18 S$ and Amgpcr19 quantified as described above, with minor modifications. For trials 1 and 2, pooled brains were immediately placed into $1-\mathrm{mL}$

Table 1. Real-time qPCR primer designs and assay parameters

\begin{tabular}{|c|c|c|c|}
\hline Gene & Primer designs & $\begin{array}{l}\mathrm{RE} \\
(\%)\end{array}$ & $\begin{array}{l}\mathrm{MP} \\
\left({ }^{\circ} \mathrm{C}\right)\end{array}$ \\
\hline Amdop1 & $\begin{array}{l}\text { 5'-TGAACGATCTCCTCGGCTAT (forward) } \\
\text { 5'-ACCCAACGACCGTATCTG AG (reverse) }\end{array}$ & 100 & 84 \\
\hline Amdop2 & $\begin{array}{l}\text { 5'-GGATCAACAGCGGAATGAAT (forward) } \\
\text { 5'-GCGATTCTTTGACTCGGTTT (reverse) }\end{array}$ & 99 & 86 \\
\hline Amdop3 & $\begin{array}{l}\text { 5'-CCATCTTCAATCTCGTAGCAATC } \\
\text { (forward) } \\
\text { 5'-AGACCAACAGTATCGTCAACCAC } \\
\text { (reverse) }\end{array}$ & 99 & 80 \\
\hline Amoa1 & $\begin{array}{l}\text { 5'-GAACGCCATCCAAGTGTTCT (forward) } \\
\text { 5'-GTCCTTCCAACCCTGTTGAT (reverse) }\end{array}$ & 100 & 84 \\
\hline Amgpcr19 & $\begin{array}{l}\text { 5'-GGATATCGTGTGTCGTCTCG (forward) } \\
\text { 5'-CTCGTAACGCAATGGTTTCC (reverse) }\end{array}$ & 95 & 79 \\
\hline 185 & $\begin{array}{l}\text { 5'-ACCCTGCTAAATAGACGTAACTTATGG } \\
\text { 5'-GATTTGTTTGTACGTTGGTAGTAAAAACC }\end{array}$ & 95 & 80 \\
\hline
\end{tabular}

(RE) Reaction efficiency, (MP) product melting point.
RNAlater (Ambion) and stored at $4^{\circ} \mathrm{C}$ for $4-7 \mathrm{~d}$ until RNA extraction. For trial 3, dissected whole brains were immediately frozen on dry ice and stored at $-80^{\circ} \mathrm{C}$ until RNA extraction. Tissue was homogenized in 5-mL tubes using a high-performance disperser (Ultra-Turrax T25, IKA-Labortechnik) for 10-15 sec in 0.5 $\mathrm{mL}$ of TRIZOL (Sigma-Aldrich). RNA was extracted by the addition of $100-\mu \mathrm{L}$ chloroform and centrifugation. RNA purification of the aqueous phase was carried out initially using an equal volume of RNAse-free 70\% ethanol, and then continued using a "Micro-to-Midi" Total RNA Purification System (Invitrogen). Synthesis of cDNA was performed using 100-ng total RNA and SuperScript III Reverse Transcriptase (Invitrogen). qPCR assays were performed using SYBR GreenER SuperMix Universal (Invitrogen), with all reactions performed in triplicate. All target geneexpression levels in QMP+ and QMP - samples were normalized to expression levels of $18 \mathrm{~S}$ (annealing temperature $55^{\circ} \mathrm{C}$ ). Mean expression levels were normalized to the mean of values detected in QMP - bees, and differences in mean transcript expression levels between young bees reared in the presence and absence of QMP were analyzed using paired two-sample $t$-tests with equal variances assumed between groups.

\section{Comparison of receptor gene expression levels in good vs. poor learners}

To compare levels of amine-receptor gene expression in the brains of good and poor learners, bees were conditioned to associate an odor with either food reward (appetitive learning) or electric shock (aversive conditioning). In each of six conditioning trials, bees were presented with a 5-sec puff of the odor eugenol. Three seconds after odor onset, bees were presented with either sucrose stimulation of the antennae followed by a 3-sec food reward (appetitive conditioning) or a 2-sec electric shock stimulus (aversive conditioning), as described above. One hour after the final conditioning trial a retention test was performed and a record was taken of whether or not the bee responded to the odor without reinforcement. Learning performances of individual bees were assessed as follows. In the case of aversive learning, "learners" were defined as bees that responded to the conditioned stimulus after the second conditioning trial and continued to display a conditioned response in all subsequent trials and in the retention test. "Nonlearners" were bees that failed to respond to the odor either during the conditioning trials or in the retention test, but which consistently responded with sting extension in response to electric shock (US). The remaining bees were defined as "intermediate responders" and were not examined further. During aversive conditioning, any bee that failed to display reflexive sting extension in response to electric shock in more than one conditioning trial, or following the retention test, was excluded (9.54\% of bees). In the case of appetitive learning, only a small percentage of bees failed to respond at all to the conditioned stimulus, while continuing to display reflexive proboscis extension when the antennae were stimulated with sucrose ("nonlearners"). However, as $85 \%-95 \%$ of foragers displayed a conditioned response at least once during the six conditioning trials, nonlearners were grouped together with "poor learners" to give adequate sample sizes. "Poor learners" were defined as bees that began to respond to the conditioned stimulus only in one of the last two conditioning trials, or in the retention test $(3.9 \%$ of bees tested). In contrast to these poor performers, bees that responded to the conditioned stimulus in the second conditioning trial, in all subsequent trials, and in the retention test were selected as "excellent learners." Bees defined as "intermediate responders" were excluded from further analysis. For appetitive conditioning, any bee that extended its proboscis to the odor stimulus alone prior to conditioning was excluded $(<1 \%$ of bees tested). Learning performances were examined in three independent experiments performed at different times of the year, both for appetitive conditioning (experiment $1, n=104$; experiment $2 n=70$; experiment $3, n=111$ ) and for aversive conditioning (experiment 1, $n=51$; experiment $2, n=59$; experiment $3, n=$ 78). Good and poor learners were identified in each experiment 
as described above and the brains of these bees (10 from each learning group) were used to compare levels of amine-receptor gene expression in bees that performed well vs. bees that performed poorly in the behavioral assays.

To analyze gene expression levels in learners vs. nonlearners, RNA extraction, cDNA synthesis, and quantification of gene expression levels were performed as described above for the QMP treatment experiments. All target gene mean expression levels in learner and poor/nonlearner samples were normalized to mean expression levels of $18 \mathrm{~S}$ (annealing temperature $55^{\circ} \mathrm{C}$ ). Mean expression levels were normalized to the mean values detected in learners, and differences in mean transcript expression levels between learners and poor/nonlearners were analyzed using paired two-sample $t$-tests with equal variances assumed between groups. All statistical analyses were performed using the software programs Minitab 15.0 and SPSS 17.0, with a 5\% level of significance accepted for all tests.

\section{Acknowledgments}

We thank Kim Garrett for maintaining the honeybee colonies and Asher Flatt for assistance with the behavioral assays. This work was funded by a grant from the Marsden Fund of the Royal Society of New Zealand (UOO0615). All of the experimental procedures outlined in this work were carried out in accordance with current New Zealand laws on animal experimentation.

\section{References}

Abramson CI, Stone SM, Ortez RA, Luccardi A, Vann KL, Hanig KD, Rice J. 2000. The development of an ethanol model using social insects I: Behavior studies of the honeybee (Apis mellifera L.). Alcohol Clin Exp Res 24: $1153-1166$.

Agarwal M, Giannoni Guzman M, Morales-Matos C, Del Valle Diaz RA, Abramson CI, Giray T. 2011. Dopamine and octopamine influence avoidance learning of honeybees in a place preference assay. PLoS One 6: e25371.

Amdam GV, Hartfelder K, Norberg K, Hagen A, Omholt SW. 2004. Altered physiology in worker honeybees (Hymenoptera: Apidae) infested with the mite Varroa destructor (Acari: Varroidae): A factor in colony loss during overwintering? J Econ Entomol 97: 741-747.

Amdam GV, Page RE Jr, Fondrk MK, Brent CS. 2010. Hormone response to bidirectional selection on social behavior. Evol Dev 12: 428-436.

Beggs KT, Glendining KA, Marechal NM, Vergoz V, Nakamura I, Slessor KN, Mercer AR. 2007. Queen pheromone modulates brain dopamine function in worker honeybees. Proc Natl Acad Sci 104: 2460-2464.

Berry JA, Cervantes-Sandoval I, Nicholas EP, Davis RL. 2012. Dopamine is required for learning and forgetting in Drosophila. Neuron 74: 530-542.

Bitterman ME, Menzel R, Fietz A, Schafer S. 1983. Classical conditioning of proboscis extension in honeybees (Apis mellifera). J Comp Psychol 97: 107-119.

Bozic J, Abramson CI, Bedencic M. 2006. Reduced ability of ethanol drinkers for social communication in honeybees (Apis mellifera carnica Poll.). Alcohol 38: 178-183.

Burke CJ, Huetteroth W, Owald D, Perisse E, Krashes MJ, Das G, Gohl D, Silies M, Certel S, Waddell S. 2012. Layered reward signalling through octopamine and dopamine in Drosophila. Nature 492: 433-437.

Crailsheim K. 1985. Distribution of haemolymph in the honeybee (Apis mellifica) in relation to season, age and temperature. J Insect Physiol 31: 707-713.

Fluri P, Lüscher M, Wille H, Gerig L. 1982. Changes in weight of the pharyngeal gland and haemolymph titres of juvenile hormone, protein and vitellogenin in worker honeybees. J Insect Physiol 28: 61-68.

Friedrich A, Thomas U, Müller U. 2004. Learning at different satiation levels reveals parallel functions for the cAMP-protein kinase A cascade in formation of long-term memory. J Neurosci 24: 4460-4468.

Giurfa M. 2007. Behavioral and neural analysis of associative learning in the honeybee: A taste from the magic well. J Comp Physiol A 193: $801-824$.

Giurfa M, Sandoz JC. 2012. Invertebrate learning and memory: Fifty years of olfactory conditioning of the proboscis extension response in honeybees. Learn Mem 19: 54-66.

Granger NA, Sturgis SL, Ebersohl R, Geng C, Sparks TC. 1996. Dopaminergic control of corpora allata activity in the larval tobacco hornworm, Manduca sexta. Arch Insect Biochem Physiol 32: 449-466.

Grozinger CM, Sharabash NM, Whitfield CW, Robinson GE. 2003. Pheromone-mediated gene expression in the honeybee brain. Proc Natl Acad Sci 100: 14519-14525.
Gruntenko NE, Rauschenbach IY. 2008. Interplay of JH, 20E and biogenic amines under normal and stress conditions and its effect on reproduction. J Insect Physiol 54: 902-908.

Gruntenko NE, Karpova EK, Adonyeva NV, Chentsova NA, Faddeeva NV, Alekseev AA, Rauschenbach IY. 2005. Juvenile hormone, 20-hydroxyecdysone and dopamine interaction in Drosophila virilis reproduction under normal and nutritional stress conditions. J Insect Physiol 51: 417-425.

Gruntenko NE, Karpova EK, Alekseev AA, Chentsova NA, Bogomolova EV, Bownes M, Rauschenbach IY. 2007. Effects of octopamine on reproduction, juvenile hormone metabolism, dopamine, and 20-hydroxyecdysone contents in Drosophila. Arch Insect Biochem Physiol 65: $85-94$.

Hammer M. 1993. An identified neuron mediates the unconditioned stimulus in associative olfactory learning in honeybees. Nature 366: $59-63$.

Hammer M. 1997. The neural basis of associative reward learning in honeybees. Trends Neurosci 20: 245-252.

Hammer M, Menzel R. 1998. Multiple sites of associative odor learning as revealed by local brain microinjections of octopamine in honeybees. Learn Mem 5: 146-156.

Han KA, Millar NS, Grotewiel MS, Davis RL. 1996. DAMB, a novel dopamine receptor expressed specifically in Drosophila mushroom bodies. Neuron 16: 1127-1135.

Hartfelder K, Bitondi MMG, Santana WC, Simoes ZLP. 2002. Ecdysteroid titer and reproduction in queens and workers of the honeybee and of a stingless bee: Loss of ecdysteroid function at increasing levels of sociality? Insect Biochem Mol Biol 32: 211-216.

Hauser F, Cazzamali G, Williamson M, Blenau W, Grimmelikhuijzen CJ. 2006. A review of neurohormone GPCRs present in the fruitfly Drosophila melanogaster and the honeybee Apis mellifera. Prog Neurobiol 80: 1-19.

Huang Z, Robinson G. 1995. Seasonal changes in juvenile hormone titers and rates of biosynthesis in honeybees. J Comp Physiol B 165: $18-28$.

Ishimoto H, Sakai T, Kitamoto T. 2009. Ecdysone signaling regulates the formation of long-term courtship memory in adult Drosophila melanogaster. Proc Natl Acad Sci 106: 6381-6386.

Kaatz H-H, Hildebrandt H, Engels W. 1992. Primer effect of queen pheromone on juvenile hormone biosynthesis in adult worker honeybees. J Comp Physiol B 162: 588-592.

Kim YC, Lee HG, Han KA. 2007. D1 dopamine receptor dDA1 is required in the mushroom body neurons for aversive and appetitive learning in Drosophila. J Neurosci 27: 7640-7647.

Krashes MJ, DasGupta S, Vreede A, White B, Armstrong JD, Waddell S. 2009. A neural circuit mechanism integrating motivational state with memory expression in Drosophila. Cell 139: 416-427.

Kuwabara M. 1957. Bildung des bedingten reflexes von Pavlovs typus bei der honigbiene, Apis mellifica. J Fac Sci, Hokkaido Univ (Zoology) 13: $458-464$.

Liu C, Pierr-Yves P, Yamagata N, Pfeiffer BD, Aso Y, Friedrich AB, Siwanosicz I, Rubin GM, Preat T, Tanimoto H. 2012. A subset of dopamine neurons signals reward for odour memory in Drosophila. Nature 488: 512-516.

Lutz CC, Rodriguez-Zas SL, Fahrbach SE, Robinson GE. 2011. Transcriptional response to foraging experience in the honey bee mushroom bodies. Develop Neurobiol 72: 153-166.

Maze IS, Wright GA, Mustard JA. 2006. Acute ethanol ingestion produces dose-dependent effects on motor behavior in the honeybee (Apis mellifera). J Insect Physiol 52: 1243-1253.

McQuillan HJ, Nakagawa S, Mercer AR. 2012. Mushroom bodies of the honeybee brain show cell-population-specific plasticity in expression of amine-receptor genes. Learn Mem 19: 151-158.

Menzel R, Müller U. 1996. Learning and memory in honeybees: From behavior to neural substrates. Annu Rev Neurosci 19: 379-404.

Menzel R, Müller U. 2001. Neurobiology. Learning from a fly's memory. Nature 411: 433-434.

Mery F, Kawecki TJ. 2003. A fitness cost of learning ability in Drosophila melanogaster. Proc Roy Soc Lond B 270: 2465-2469.

Mery F, Belay AT, So AK, Sokolowski MB, Kawecki TJ. 2007. Natural polymorphism affecting learning and memory in Drosophila. Proc Natl Acad Sci 104: 13051-13055.

Müller U. 2006. Memory: Cellular and molecular networks. Cell Mol Life Sci 63: $961-962$.

Mustard JA, Wright GA, Edgar EA, Mazade RE, Wu C, Lillvis JL. 2008. Acute ethanol ingestion impairs appetitive olfactory learning and odor discrimination in the honeybee. Neurobiol Learn Mem 90: 633-643.

Pankiw T, Huang ZY, Winston ML, Robinson GE. 1998. Queen mandibular gland pheromone influences worker honeybee (Apis mellifera L.) foraging ontogeny and juvenile hormone titers. Insect Physiol 44: 685-692.

Paul RK, Takeuchi H, Matsuo Y, Kubo T. 2005. Gene expression of ecdysteroid regulated gene E74 of the honeybee in ovary and brain. Insect Mol Biol 14: 9e15. 
Paul RK, Takeuchi H, Kubo T. 2006. Expression of two ecdysteroid-regulated genes, Broad-Complex and E75, in the brain and ovary of the honeybee (Apis mellifera L.). Zool Sci 23: 1085-1092.

Purnell MT, Mitchell CJ, Taylor DJ, Kokay IC, Mercer AR. 2000. The influence of endogenous dopamine levels on the density of $[3 \mathrm{H}] \mathrm{SCH} 23390$-binding sites in the brain of the honeybee, Apis mellifera L. Brain Res 855: 206-216.

Raikhel AS, Brown MR, Belles X. 2004. Hormonal control of reproductive processes. In Comprehensive molecular insect science, Vol. 3 (ed. Gilbert LI, et al.), pp. 433-491. Elsevier, Oxford, UK.

Riddiford LM, Cherbas P, Truman JW. 2000. Ecdysone receptors and their biological actions. Vit Horm 60: 1-73.

Riemensperger T, Voller T, Stock P, Buchner E, Fiala A. 2005. Punishment prediction by dopaminergic neurons in Drosophila. Curr Biol 15: $1953-1960$

Robinson GE, Strambi C, Strambi A, Feldlaufer MF. 1991. Comparison of juvenile hormone and ecdysteroid haemolymph titres in adult worker and queen honeybees (Apis mellifera). J Insect Physiol 37: 929-935.

Roussel E, Carcaud J, Sandoz JC, Giurfa M. 2009. Reappraising social insect behavior through aversive responsiveness and learning. PLoS One 4: e4197.

Schroll C, Riemensperger T, Bucher D, Ehmer J, Völler T, Erbguth K, Gerber B, Hendel T, Nagel G, Buchner E. 2006. Light-induced activation of distinct modulatory neurons triggers appetitive or aversive learning in Drosophila larvae. Curr Biol 16: 1741-1747.

Schwärzel M, Monastirioti M, Scholz H, Friggi-Grelin F, Birman S, Heisenberg M. 2003. Dopamine and octopamine differentiate between aversive and appetitive olfactory memories in Drosophila. J Neurosci 23: $10495-10502$.

Selcho M, Pauls D, Han KA, Stocker RF, Thum AS. 2009. The role of dopamine in Drosophila larval classical olfactory conditioning. PLoS One 4: e5897.
Srivastava DP, Yu EJ, Kennedy K, Chatwin H, Reale V, Hamon M, Smith T, Evans PD. 2005. Rapid, nongenomic responses to ecdysteroids and catecholamines mediated by a novel Drosophila G-protein-coupled receptor. J Neurosci 25: 6145-6155.

Takeda K. 1961. Classical conditioned response in the honeybee. J Insect Physiol 6: $168-179$.

Takeuchi H, Paul RK, Matsuzaka E, Kubo T. 2007. EcR-A expression in the brain and ovary of the honeybee (Apis mellifera L.). Zool Sci 24: 596-603.

Truman JW, Riddiford LM. 2002. Endocrine insights into the evolution of metamorphosis in insects. Annu Rev Entomol 47: 467-500.

Velarde RA, Robinson GE, Fahrbach SE. 2006. Nuclear receptors of the honeybee: Annotation and expression in the adult brain. Insect Mol Biol 15: $583-595$.

Velarde RA, Robinson GE, Fahrbach SE. 2009. Coordinated responses to developmental hormones in the Kenyon cells of the adult worker honeybee brain (Apis mellifera L.). J Insect Physiol 55: 59-69.

Vergoz V, Roussel E, Sandoz JC, Giurfa M. 2007a. Aversive learning in honeybees revealed by the olfactory conditioning of the sting extension reflex. PLoS One 2: e288.

Vergoz V, Schreurs HA, Mercer AR. 2007b. Queen pheromone blocks aversive learning in young worker bees. Science 317: 384-386.

Yamazaki Y, Shirai K, Paul RK, Fujiyuki T, Wakamoto A, Takeuchi H, Kubo T. 2006. Differential expression of HR38 in the mushroom bodies of the honeybee brain depends on the caste and division of labor. FEBS Lett 580: $2667-2670$.

Yamazaki Y, Kiuchi M, Takeuchi H, Kubo T. 2011. Ecdysteroid biosynthesis in workers of the European honeybee Apis mellifera L. Insect Biochem Mol Biol 41: 283-293.

Received February 21, 2013; accepted in revised form April 24, 2013. 


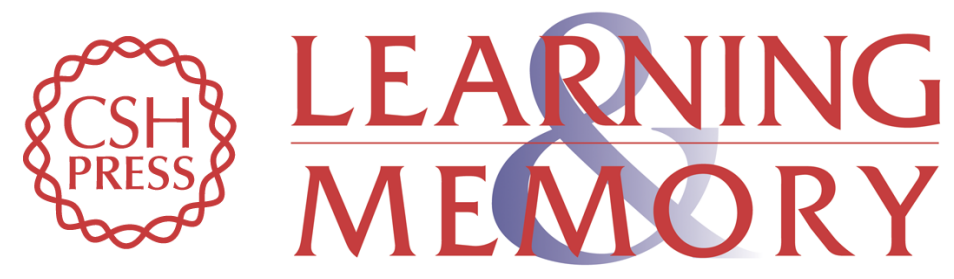

\section{Steroid hormone (20-hydroxyecdysone) modulates the acquisition of aversive olfactory memories in pollen forager honeybees}

Lisa H. Geddes, H. James McQuillan, Alastair Aiken, et al.

Learn. Mem. 2013, 20:

Access the most recent version at doi:10.1101//m.030825.113

\begin{aligned} & \hline References $\begin{array}{l}\text { This article cites } 63 \text { articles, } 12 \text { of which can be accessed free at: } \\ \text { http://learnmem.cshlp.org/content/20/8/399.full.html\#ref-list-1 }\end{array} \\ & \begin{array}{r}\text { Creative } \\ \text { Commons } \\ \text { License }\end{array} \begin{array}{l}\text { This article is distributed exclusively by Cold Spring Harbor Laboratory Press for the } \\ \text { first } 12 \text { months after the full-issue publication date (see } \\ \text { http://learnmem.cshlp.org/site/misc/terms.xhtml). After } 12 \text { months, it is available under } \\ \text { a Creative Commons License (Attribution-NonCommercial } 3.0 \text { Unported), as } \\ \text { described at http://creativecommons.org/licenses/by-nc/3.0/. }\end{array} \\ & \begin{array}{c}\text { Receive free email alerts when new articles cite this article - sign up in the box at the } \\ \text { top right corner of the article or click here. }\end{array} \\ & \begin{array}{c}\text { Service } \\ \text { terting }\end{array}\end{aligned}$ 